ledge of these languages acquired is not more than sufficient for purely scientific purposes, every Englishman has, in his native tongue, an almost perfect instrument of literary expression; and, in his own literature, models of every kind of literary excellence. If an Englishman cannot get literary culture out of his Bible, his Shakspere, his Milton, neither, in my belief, will the profoundest study of Homer and Sophocles, Virgil and Horace, give it to him.

Thus, since the constitution of the College makes sufficient provision for literary as well as for scientific education, and since artistic instruction is also contemplated, it seems to me that a fairly complete culture is offered to all who are willing to take advantage of it.

But I am not sure that at this point the "practical" man, scotched but not slain, may ask what all this talk about culture has to do with an Institution, the object of which is defined to be "to promote the prosperity of the manufactures and the industry of the country." He may suggest that what is wanted for this end is not culture, nor even a purely scientific discipline, but simply a knowledge of applied science.

I often wish that this phrase, "applied science," had never been invented. For it suggests that there is a sort of scientific knowledge of direct practical use, which can be studied apart from another sort of scientific knowledge, which is of no practical utility, and which is termed "pure science." But there is no more complete fallacy than this. What people call applied science is nothing but the application of pure science to particular classes of problems. It consists of deductions from those general principles, established by reasoning and observation, which constitute pure science. No one can safely make these deductions until he has a firm grasp of the principles; and he can obtain that grasp only by personal experience of the processes of observation and of reasoning on . which they are founded.

Almost all the processes employed in the arts and manufactures fall within the range either of physics or of chemistry. In order to improve them, one must thoroughly understand them; and no one has a chance of really understanding them who has not obtained that mastery of principles and that habit of dealing with facts which is given by long-continued and well-directed purely scientific training in the physical and the chemical laboratory. So that there really is no question as to the necessity of purely scientific discipline, even if the work of the College were limited by the narrowest interpretation of its stated aims.

And, as to the desirableness of a wider culture than that yielded by science alone, it is to be recollected that the improvement of manufacturing processes is only one of the conditions which contribute to the prosperity of industry. Industry is a means and not an end; and mankind work only to get something which they want. What that something is depends partly on their innate, and partly on their acquired, desires.

If the wealth resulting from prosperous industry is to be spent upon the gratification of unworthy desires; if the in creasing perfection of manufacturing processes is to be accom. panied by an increasing debasement of those who carry them on, I do not see the good of industry and prosperity.

Now it is perfectly true that men's views of what is desirable depend upon their characters; and that the innate proclivities to which we give that name are not touched by any amount of instruction. But it does not follow that even mere intellectual education may not, to an indefinite extent, modify the practical manifestation of the characters of men in their actions, by supplying them with motives unknown to the ignorant. A pleasure-loving character will have pleasure of some sort; but, if you give him the choice, he may prefer pleasures which do not degrade him to those which do. And this choice is offered to every man, who possesses in literary or artistic culture a neverfailing source of pleasures, which are neither withered by age, nor-staled by custom, nor embittered in the recollection by the pangs of self-reproach.

If the Institution opened to-day fulfils the intention of its founder, the picked intelligences among all classes of the population of this district will pass tbrough it. No child born in Birmingham, henceforward, if he have the capacity to profit by the opportunities offered to him first in the primary and other schools, and afterwards in the Scientific College, need fail to obtain, not merely the instruction, but the culture most appropriate to the conditions of his life.
Within these walls, the future employer and the future artisan may sojourn together for a while, and carry through all their lives the stamp of the influences then brought to bear upon them. Hence, it is not beside the mark to remind you that the prosperity of industry depends not merely upon the improvement of manufacturing processes, not merely upon the ennobling of the individual character, but upon a third condition, namely, a clear understanding of the conditions of social life on the part of both the capitalist and the operative, and their agreement upon common principles of social action. They must learn that social phenomena are as much the expression of natural laws as any others; that no social arrangements can be permanent unless they harmonise with the requirements of social statics and dynamics; and that, in the nature of things, there is an arbiter whose decisions execute themselves.

But this knowledge is only to be obtained by the application of the methods of investigation adopted in physical researches to the investigation of the phenomena of society. Hence, I confess, I should like to see one addition made to the excellent scheme of education propounded for the College, in the shape of provision for the teaching of Sociology. For though we are all agreed that party politics are to have no place in the instruction of the College; yet in this country, practically governed as it is now by universal suffrage, every man who does his duty must exercise political functions. And if the evils which are inseparable from the good of political liberty are to be checked, if the perpetual oscillation of nations between anarchy and despotism is to be replaced by the steady march of self-restraining freedom; it will be because men will gradually bring themselves to deal with political, as they now deal with scientific questions; to be as ashamed of undue haste and partisan prejudice in the one case as in the other; and to believe that the machinery of society is at least as delicate as that of a spinning-jenny, and not more likely to be improved by the meddling of those who have not taken the trouble to master the principles of its action.

In conclusion, I am sure that I make myself the mouthpiece of all present in offering to the venerable Founder of the Institution, which now commences its beneficent career, our congratu. lations on the completion of his work; and in expressing the conviction, that the remotest posterity will point to it as a crucial instance of the wisdom which natural piety leads all men to ascribe to their ancestors.

ON A SEPTUM PERMEABLE TO WATER, $A N D$ IMPERMEABLE TO AIR, WITH APPLICATION TO A NAVIGATIONAL DEPTH GAUGE ${ }^{1}$

A SMALL quantity of water in a capillary tube, with both $A$ ends in air, acts as a perfectly air-tight plug against difference of pressure of air at its two ends, equal to the hydrostatic pressure corresponding to the height at which water stands in the same capillary tube when it is held upright, with one end under water and the other in air. And if the same capillary tube be held completely under water, it is perfectly permeable to the water, opposing no resistance except that due to viscidity, and permitting a current of water to flow through it with any difference of pressure at its two ends, however small. In passing it may be remarked that the same capillary tube is, when not plugged by liquid, perfectly permeable to air.

A plate of glass, or other solid, capable of being perfectly wet by water, with a hole bored through it, acts similarly in letting air pass freely through it when there is no water in the hole; and letting water pass freely through it when it is held under water; and resisting a difference of air-pressures at the two sides of it when the hole is plugged by water. The difference of air-pressures on the two sides which it resists is equal to the hydrostatic pressure corresponding to the rise of water in a capillary tube of the same diameter as the narrowest part of the hole. Thus a metal plate with a great many fine perforations, like a very fine rose for a watering-can for flowers, fulfils the conditions stated in the title to this communication. So does very fine wire clotb. The finer the holes, the greater is the difference of air-pressures balanced, when they are plugged with water. The shorter the length of each hole the less it resists the passage of water when completely submerged; and the greater the number of holes, the less is the whole resistance to the permeation of water through the membrane.

I Paper read at the British Association by Sir William Thomson. 
Hence, clearly, the object indicated in the title is more perfectly attained, the thinner the plate and the smaller and more numerous the holes. Very fine wire cloth would answer the purpose better than any metal plate with holes drilled through it ; and very fine closely-woven cotton cloth, or cambric, answers better than the finest wire cloth. The impenetrability of wet cloth to air is well known to laundresses, and to every naturalist who has ever chanced to watch their operations. The quality of dry cloth to let air through with considerable freedom, and wet cloth to resist it, is well known to sailors, wet sails being sensibly more effective than dry sails (and particularly so in the case of old sails, and of sails of thin and light material).

An illustration was shown to the meeting by taking an Argand lamp-funnel, with a piece of very fine closely-woven cotton cloth tied over one end of it. When the cloth was dry, and the other end dipped under water, the water rose with perfect freedom inside, showing exceedingly little resistance to the passage of air through the dry cloth. When it was inverted, and the end guarded by the cloth was held under water, the water rose with very great freedom, showing exceedingly little resistance to the permeation of water through the cloth. The cloth being now wet, and the glass once more held with its other end under water, the cloth now seemed perfectly air-tight, even when pressed with air-pressure corresponding to nine inches of water, by forcing down the funnel, which was about nine inches long, till the upper end was nearly submerged. When it was wholly sub-

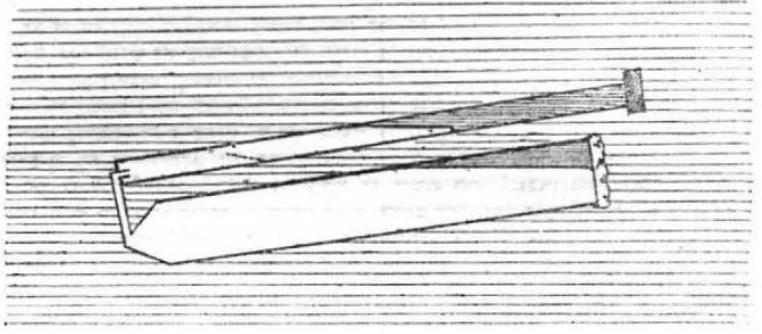

Water indicated by horizontal shading; Air by white paper.

merged, so that there was air on one side and water on the other, the resistance to permeation of air was as decided as it was when the cloth, very perfectly wet, had air on each side of it.

Once more, putting the cloth end under water; holding the tube nearly horizontal, and blowing by the mouth applied to the other end:-the water which had risen into the funnel before the mouth was applied, was expelled. After that no air escaped until the air-pressure within exceeded the water pressure on the outside of the cloth by the equivalent of a little more than nine inches of water; and when blown with a pressure just a very little more than that which sufficed to produce a bubble from any part of the cloth, bubbles escaped in a copious torrent from the whole area of the cloth.

The accompanying sketch represents the application to the Navigational Depth Gauge. The wider of the two communicating tubes, shown uppermost in the sketch, has its open mouth guarded by very fine cotton cloth tied across it. The tube shown lower in the diagram is closed for the time of use by a stopper at its lower end. A certain quantity of water (which had been forced into it during the descent of the gauge to the bottom of the sea) is retained in it while the gauge is being towed np to the surface in some such oblique position as that shown in the sketch. While this is being done the water in the wide tube is expelled by the expanding air. The object of the cloth guard is to secure that this water is expelled to the last drop before any air escapes; and that afterwards, while the gange is being towed wildly along the surface from wave to wave by a steamer running at fourteen or sixteen knots, not a drop of water shall re-enter the instrument.

\section{ON THE CLASSIFICATION OF BIRDS ${ }^{1}$}

$A$ BOUT twelve years ago Prof. Huxley had taken up the A subject of the classification of birds in his usual zealous and original way, and from quite a new point of view. Prof. Huxley, treating birds mainly from their bones and as if they were extinct

${ }^{x}$ Abstract of a paper read at the British Association by P. L. Sclater, M.A., Ph.D., F.R.S. animals of which these parts of their structure only were known, had proposed an entirely new plan of arrangement, based mainly upon the characteristic variations of the palatal bones, which had passed almost unnoticed by previous writers. The author, who had long been dissatisfied with the Cuvierian system, which with certain modifications he had employed up to 1872 , had in that year been constrained to consider the whole subject in order to decide what arrangements should be adopted in the "Nomenclator Avium Americanarum " (a joint work by Mr. O. Salon and himself), then ready for publication. Prof. Huxley had commenced his system with the lowest and most reptilian birds, and had ended it with the highest and most specialised. But it seemed to the author that by exactly reversing this arrangement he would obtain a scheme which would not very far deviate from that which he had previously employed for the first three orders, and would offer many improvements on the Cuvierian system in the remaining ones. Such a scheme had accordingly been promulgated in the Introduction to the "Nomenclator" and followed in that work. In the various subsequently issued editions of the "List of Vertebrated Animals in the Zoological Society's Gardens" a nearly similar arrangement had been followed. A certain amount of adbesion having been secured to this system, the author had been recently induced to devote some labour to its improvement and development. As now elaborated it did not profess to be in any respects original, except as regarded certain small details on points to which he had devoted special attention. The arrangement was in fact simply that of Huxley reversed, with slight modifications consequent upon the recent researches of Parker and Garrod on the anatomy and osteology of little known forms.

The author then proceeded to explain further the "Systema Avium " thus advocated, as shown in the subjoined table, in which the approximate number of known species was added after each Order.

\section{ORDERS OF EXISTING BIRDS \\ SubClass Carinate (I0,12I SPECIES)}

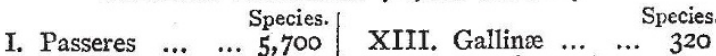

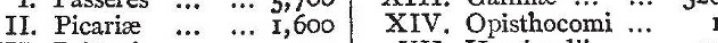

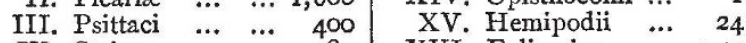

IV. Striges $\quad \cdots \quad$...

V. Accipitres... $\quad \ldots \quad 330$ XVII. Alectorides $\ldots . .60$

VI. Steganopodes ... 60 XVIII. Limicolæ $\quad \ldots \quad 250$

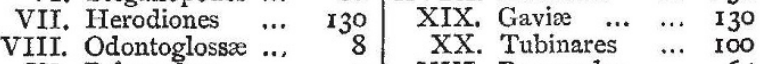

IX. Palamedeæ $\quad \ldots \quad 3$ XXI. Pygopodes $\quad \ldots \quad 65$

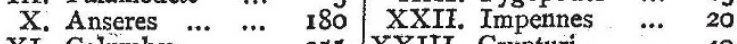

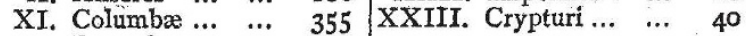
XII. Pterocletes $\ldots . \quad 15$

SUBClasS RATtTE (18 SPECIES)

\begin{tabular}{llll|lll} 
XXIV. Apteryges ... & $\ldots$ & 4 & XXVI. Struthiones & $\ldots$ & 4
\end{tabular}

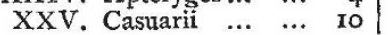

In submitting this arrangement, as one which on the whole he was disposed to regard as the best to be adopted after many years' study of the Class of Birds, the author observed that it should be recollected that, although a linear system is an absolute necessity for practical use, it could never be a perfectly natural one. It would always be found that certain groups were nearly equally related to others in different places in the linear series, and that it was a matter of difficulty to decide with which of the allied forms they were best located. But, a linear arrangement being an absolute necessity, it became our duty to make it as natural as possible.

\section{THE GREEN COLOUR OF OYSTERS}

IN NATURE, vol, xvi. p. 397 , mention was made of the fact 1 that the green colour observed in oysters in certain localities is caused by a variety of navicula, to which the name Navicula ostrearia has been given. Further particulars of experiments made by M. Puységur, at Sissable, are not without interest. ${ }^{2}$

"The green slime was collected by lightly scraping the margin of one of the 'clears' with a spoon, and was put in flasks, shaken for a moment and then allowed to settle, so as to get rid of the mud, some admixture of which is inevitable. The coloured fluid, containing little or nothing besides diatoms, was then poured off into other flasks. Care and some little dexterity are requisite, as if there is too much silt or too large a quantity

$$
\text { I Revue maritime et coloniale, February, } \mathbf{1 8 8 0} \text {. }
$$

